\title{
Larval trophodynamics, turbulence, and drift on Georges Bank: A sensitivity analysis of cod and haddock*
}

\author{
FRANCISCO E. WERNER ${ }^{1}$, BRIAN R. MACKENZIE ${ }^{2}$, R. IAN PERRY ${ }^{3}$, \\ R. GREGORY LOUGH ${ }^{4}$, CHRISTOPHER E. NAIMIE ${ }^{5}$, BRIAN O. BLANTON ${ }^{1}$ \\ and JOHN A. QUINLAN ${ }^{1,4}$ \\ ${ }^{1}$ Marine Sciences Department, University of North Carolina, Chapel Hill, NC, 27599-3300, USA. \\ ${ }^{2}$ Danish Institute for Fisheries \& Marine Research, Charlottenlund Castle, DK-2920 Charlottenlund, Denmark. \\ ${ }^{3}$ Pacific Biological Station, Department of Fisheries and Oceans, Nanaimo, BC, V9R 5K6, Canada. \\ ${ }^{4}$ National Marine Fisheries Center, Northeast Fisheries Science Center, Woods Hole, MA 02543, USA. \\ ${ }^{5}$ Dartmouth College, Hanover, NH 03755, USA.
}

\begin{abstract}
SUMMARY: Using an individual-based model approach we consider trophodynamic effects on the growth and survival of larval cod (Gadus morhua) and haddock (Melanogrammus aeglefinus) on Georges Bank during late winter/early spring. These studies represent an extension of results described in Werner et al. (1996; Deep-Sea Res. II), wherein the effect of turbulence-enhanced larval-prey contact rates increased the effective prey concentration resulting in growth of cod larvae consistent with observed rates in the field. We reformulated the feeding of the larvae to include existing relationships between maximum prey-length and larval-length and we examined: (i) larval search behaviour and its effect on encounter with prey, (ii) the ability of larvae to pursue and capture prey in a turbulent environment, and (iii) the effect of turbulence on the dispersion of larvae in the vertical. We find that search behaviour, the effect of turbulence on pursuit and capture, and vertical dispersion decrease the predicted larval growth rates compared to those observed in the earlier study. These results suggest that larval feeding behaviour, and especially the ability of larvae to pursue encountered prey, could be an important input to larval growth and survival models. The inclusion of turbulence in determining the position of passive larvae in the water column allows the larvae to sample the entire water column, contributing to a decrease in the variance of the size of the larvae over time. The ability of larvae to swim and aggregate in the vertical will be necessary to reproduce distributions observed in the field.
\end{abstract}

Key words: larval trophodynamics, turbulence, modelling, cod, haddock, Georges Bank.

\section{INTRODUCTION}

Spatially explicit individual-based models of larval fish trophodynamics can be used to explore the relative importance of biological and physical variables on larval growth and survival (e.g. Hinckley et al., 1996; Heath et al., 1998; Werner et al., 1996). Conceptually, larvae in high growth and sur-

*Received August 10, 1999. Accepted April 25, 2000. vival areas could make a greater contribution to the recruiting population if these areas also have longer retention time scales than poor growth and survival areas. Alternatively, larvae in poor growth areas could make a greater contribution if these areas have longer retention time-scales than areas of good growth which, however, experience high advective through-flows. The problem is to determine the relative magnitudes of growth rates and retention time-scales. 


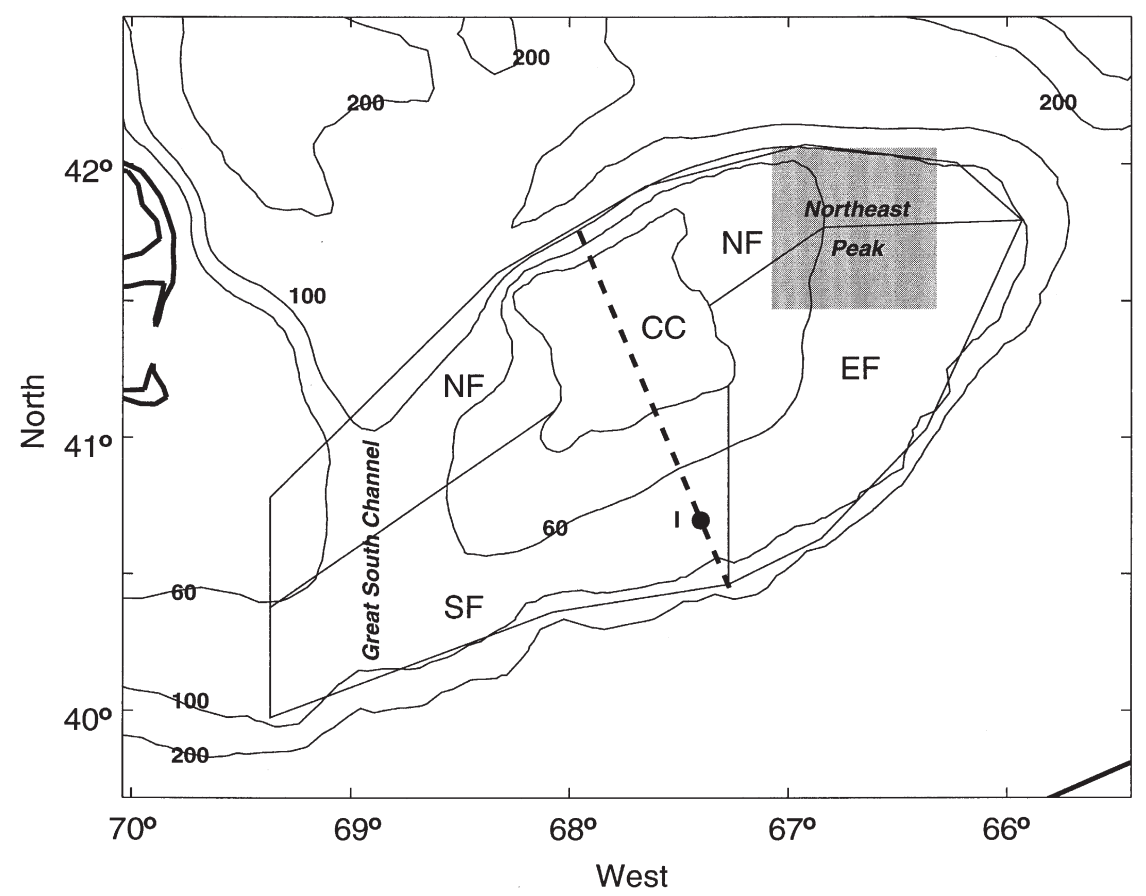

FIG. 1. - George Bank bathymetry (m) and prey field sectors. The northern flank (NF), the eastern flank (EF), the southern flank (SF) and central cap (CC) prey regions/sectors are outlined; the spawning grounds, located on the Northeast Peak, are indicated by the shaded square. The outline of the Central Cap is defined by the $40 \mathrm{~m}$ isobath. The dashed line indicates the section along which values of turbulent kinetic energy dissipation are show in Fig. 3. A time-history and vertical profile of the turbulent kinetic energy dissipation $\varepsilon$ at Site I is show in Fig. 3 .

Our studies of larval cod and haddock on Georges Bank (Fig. 1) have shown that predicted survival and growth rates for cod larvae located below the pycnocline, where the turbulenceenhanced contact rates are greatest, are comparable to those observed in the field (Werner et al., 1996). The inclusion of spatially-variable and time-dependent turbulence generated by winds and tides increased prey contact rates two- to five-fold, effectively increasing the prey concentration perceived by larvae. Thus, the region of highest retention due to circulation processes (Werner et al., 1993; Lough et al., 1994) coincides with the region of highest growth rates: shoalward of the $60 \mathrm{~m}$ isobath at subsurface depths of $25 \mathrm{~m}$ or greater. Despite the turbulence-enhanced contact rates, haddock larvae required five-fold higher prey densities to survive than did cod larvae.

In the present study we use our modelling approach to examine the sensitivity of larval cod (Gadus morhua) and haddock (Melanogrammus aeglefinus) growth and survival to representations of the larval feeding environment on Georges Bank. In particular we examine (i) larval behaviour in the determination of larval-prey contact rates, (ii) the effects of turbulence on post-encounter behaviours (capture and ingestion), and (iii) the effects of the turbulent dispersion on the vertical position of the larvae.

\section{PHYSICAL MODEL FLOW FIELD}

The three-dimensional, nonlinear, prognostic (evolving baroclinic field), finite element hydrodynamic model employed is that of Lynch et al. (1996). The model operates in tidal time and uses the quasi-equilibrium version of Mellor-Yamada level 2.5 turbulence closure scheme (Mellor and Yamada 1982; Galperin et al., 1988), by including the turbulent kinetic energy $\left(q^{2} / 2\right)$ and mixing length $(l)$ as hydrodynamic state variables that are functions of position and time.

The circulation field we use corresponds to climatological March-April conditions, consistent with the spawning and early larval drift period of cod and haddock on Georges Bank. The details of the computation are described in Naimie (1996). Forcing included the $\mathrm{M}_{2}$ tide, mean wind stress (of 0.0472 $\mathrm{Pa}$ toward 121.4 degrees clockwise from true North), and an applied nudging boundary condition at the surface -referenced to the climatological surface density- for the evolving baroclinic field. Additionally, at open boundaries the low-frequency (mean sea level set-up) and vertical structure of density are fixed at the climatological conditions (see Naimie, 1995 and 1996). The depth-averaged flow field (Fig. 2) shows the familiar clockwise pattern around Georges Bank, including the tidally rectified 


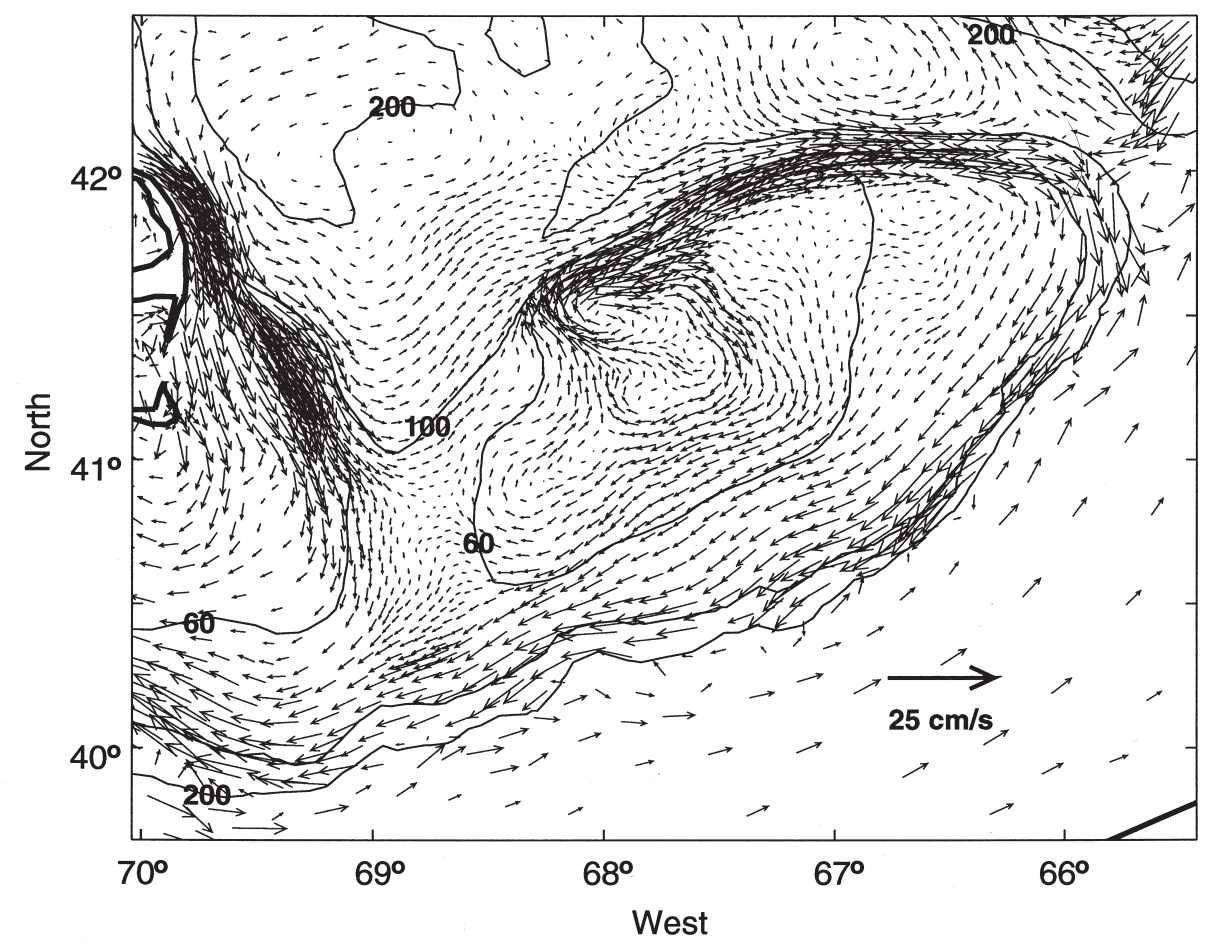

FIG. 2. - Depth-averaged residual flow field from the circulation model for the March-April period. Adapted from Werner et al. (1996).

northern flank jet, the southwestward drift along the southern flank and the generally weak recirculation in the Great South Channel during this season. The Bank-wide depth-averaged turbulent kinetic energy dissipation rate $\varepsilon(\mathrm{W} / \mathrm{Kg})$, a vertical section of $\varepsilon$ across the Bank, and a time-series at a station inside the $60 \mathrm{~m}$ isobath are shown in Figure 3. These results are generally in good agreement with Loder et al. (1993) and Horne et al. (1996).

For purposes of larval advection (i.e. particle tracking) and trophodynamic calculations we retained only the residual, $\mathrm{M}_{2}$ and $\mathrm{M}_{4}$ components of velocity, and relevant turbulent quantities; those components of velocity and turbulence at the $\mathrm{M}_{6}$ frequency do not affect our results significantly. The effect of the wind is included in the mean circulation and turbulence components. The particle (larval) positions 20, 40 and 60 days post-spawn are shown in Figure 4 for two cases: non-turbulent (as in Werner et al., 1996) and turbulent dispersal of larvae in the vertical (see Section 5.3 herein). Spawning is assumed to occur on the Northeast Peak, and the larvae drift passively with the circulation. Particles were released over the Northeast Peak at 1, 10, 20, 30,40 and $50 \mathrm{~m}$ in a square region $62.5 \mathrm{~km}$ on a side (Fig. 1). At each horizontal level there were 121 particles equally spaced in an $11 \times 11$ grid, resulting in a total of 726 particles per release. The egg-phase is assumed to be 20 days long (Page and Frank, 1989). At 20 days post-spawn the larvae hatch and trophodynamic processes (feeding, growth, starvation) begin. We consider trophodynamics only for the first 40 days of the larval period for a total simulation time of 60 days: a 20-day egg-phase and a 40-day larval-phase. We have not explicitly considered the yolksac stage in our formulation; see Gallager et al. (1996) and Quinlan et al. (1997) for studies on yolksac larval feeding and growth.

\section{PREY FIELD}

Representative concentrations of zooplankton prey and their distributions on Georges Bank for the February-April time-period were determined from the literature and assumptions detailed in Werner et al. (1996). Briefly, Kane (1984) identified the various life history stages of Pseudocalanus spp., Calanus finmarchicus, Oithona similis, and Centropages spp. as dominant components of larval cod and haddock diets on Georges Bank. Our specification of the prey field therefore concentrates on these four taxonomic groups. Georges Bank was separated into northern flank (NF), eastern flank (EF), southern flank (SF) and central cap (CC; depths of less than 40 m) regions (Fig. 1) based on Davis (1984). 

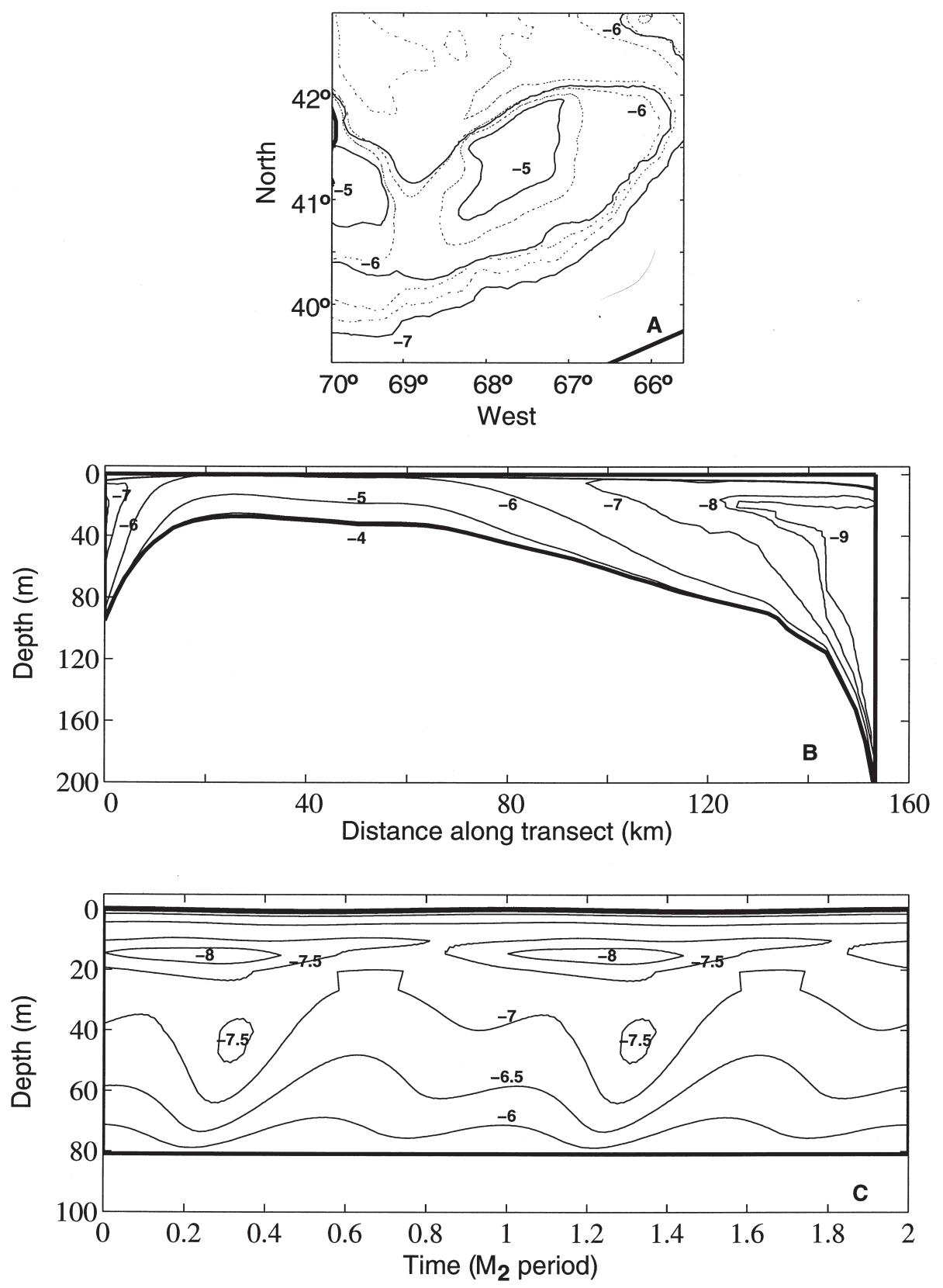

FIG. 3. - Top panel (A): depth-averaged turbulent kinetic energy dissipation rate $\log _{10} \varepsilon[\varepsilon(\mathrm{W} / \mathrm{Kg})]$ at a point in the time during the $\mathrm{M}_{2}$ tidal cycle (isobaths indicated by dotted lines); middle panel (B): vertical section of $\log _{10} \varepsilon[\varepsilon(\mathrm{W} / \mathrm{Kg})]$ across the Bank from northern (NF) to sourthern flank (SF), along the transect indicated in Fig. 1 and time as in (A); bottom panel (C): vertical profil of the turbulent kinetic energy dissipation rate $\log _{10} \varepsilon[\varepsilon(\mathrm{W} / \mathrm{Kg})]$ over two tidal cycles at Site I (Fig. 1) on the southern flank (the time series was constructed using the residual, $M_{2}$ and $M_{4}$ components).

Table 1 summarises prey sizes and weights, and assigned concentrations within each of the four regions on Georges Bank for late-winter/early spring. These distributions were prescribed as time-invariant and vertically uniform within each region. Although we recognise that this as an artificial constraint, it is justified as a first simplifying assumption consistent with the relatively small difference in regional abundances of major prey items, as well as the absence of persistent vertical stratification between February and
March-April. Additionally, we assumed that larval fish feeding had no impact on prey abundance or distribution (e.g. Cushing, 1983). These are the same prey fields estimates used in Werner et al. (1996).

In nature, plankton are patchily distributed at small spatial scales. For example, in both calm and turbulent conditions off Peru and California, Owen (1989) found patches of plankton at scales of 0.2-2 $\mathrm{m}$, and plankton abundance within the patches were typically 2-4 times greater than outside the patches. 
TABLE 1. - Egg and zooplankton prey type, mean size (length), mean weight (dry weight) and standard deviation ( $\sigma$ ) of each size class, and assigned concentrations within each of the four regions on Georges Bank (northern flank, eastern flank, southern flank, central cap).

\begin{tabular}{|c|c|c|c|c|c|c|}
\hline $\begin{array}{l}\text { Prey } \\
\text { Type }\end{array}$ & 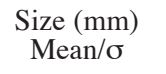 & $\begin{array}{l}\text { Weight } \\
(\mu \mathrm{gDW})\end{array}$ & $\begin{array}{c}\text { N.Flank } \\
\text { \#/liter }\end{array}$ & $\begin{array}{c}\text { E.Flank } \\
\text { \#/liter }\end{array}$ & $\begin{array}{c}\text { S.Flank } \\
\text { \#/liter }\end{array}$ & $\begin{array}{l}\text { C.Cap } \\
\text { \#/liter }\end{array}$ \\
\hline Eggs & $<0.13 / 0.005$ & 1.60 & 2.14 & 2.14 & 2.14 & 2.14 \\
\hline Nauplii & $0.28 / 0.05$ & 1.20 & 1.08 & 12.30 & 6.36 & 12.78 \\
\hline C-I & $0.42 / 0.05$ & 1.10 & 0.05 & 0.49 & 0.22 & 0.62 \\
\hline C-II & $0.52 / 0.05$ & 1.82 & 0.05 & 0.32 & 0.24 & 0.35 \\
\hline C-III & $0.62 / 0.05$ & 2.89 & 0.02 & 0.08 & 0.22 & 0.12 \\
\hline C-IV & $0.73 / 0.05$ & 4.80 & 0.04 & 0.08 & 0.27 & 0.11 \\
\hline $\mathrm{C}-\mathrm{V}$ & $0.88 / 0.05$ & 9.58 & 0.04 & 0.07 & 0.31 & 0.11 \\
\hline C-VI & $>0.88 / 0.05$ & 16.67 & 0.18 & 0.11 & 0.24 & 0.06 \\
\hline
\end{tabular}

In nearshore waters off Massachusetts, Davis et al. (1991) found patches of copepods at scales of 20-30 $\mathrm{cm}$. On Georges Bank the distribution of plankton at such small scales is currently under study, but given the presence of small-intermediate scale patchiness in other systems (e.g. Jenkins, 1989) we expect that plankton on the Bank will be patchily distributed at similar spatial scales. Incze et al. (1996) found that some stratified sites on Georges Bank had concentrations of nauplii four to sixteen times the integrated $(0-50 \mathrm{~m})$ abundance. Since the data in Table 1 were derived from towed plankton nets that do not detect small scale patchiness, we feel that these concentrations may be low. To explore the sensitivity to prey field specification, we increased the concentration of the four smallest prey classes in some of the studies below.

\section{TROPHODYNAMIC MODEL}

The core of our model (described in Werner et al., 1996) is the standard bioenergetic supplydemand function, in which growth is represented as the difference between the amount of food absorbed by a larva and daily metabolic costs, (e.g. Beyer and Laurence, 1981; Laurence 1985). The sequence of the model computations remain as in Werner et al. (1996), i.e. given (i) larval size at hatch, (ii) daily metabolic costs and (iii) prey encountered, then (iv) the prey ingested are estimated, (v) daily growth is computed and compared to (vi) a minimum larval size. If the size of a larva falls below this minimum at any time, that larva is considered dead. We have reformulated our approach in estimating the number of prey encountered and the prey biomass ingested [components (iii) and (iv)]; these are described next. The formulations for components (i), (ii), (v) and (vi) are as in Werner et al. (1996). (a) Prey Encounters. Rothschild and Osborn (1988) discussed the role of turbulence in affecting (enhancing) encounter rates with planktonic prey. Subsequent studies and reviews, (e.g. Sundby and Fossum, 1990; MacKenzie and Leggett, 1991; Muelbert et al., 1994; Werner et al., 1996; Alcaraz et al., 1997; Marrasé et al., 1997), have enhanced our understanding of the role of turbulence in fluid flows, finding effective increases in contact rates of 2-10 in laboratory and field (wind- and tidally-driven) conditions.

In the calculations that follow, we will consider cod (and haddock) larvae as pause-travel predators, and use the relationship derived by MacKenzie and Kiørboe (1995)

$E_{p-t}(i)=2 / 3 \pi R^{3} p(i) P_{F}+\pi R^{2} p(i)\left(u_{\text {prey }}^{2}+2 \omega^{2}\right)^{0.5} P_{F} P_{D}$

to estimate the encounter rate (prey/sec). Here $R$ is the larval reactive distance (taken as $0.8 \mathrm{x}$ bodylength of the larva), $P_{F}$ is the pause frequency (\#/sec), $P_{D}$ is the pause duration (sec), $p(i)$ is the ith prey concentration and $u_{\text {prey }}$ is the prey swimming speed taken to be one body-length per second. Following MacKenzie and Kiørboe (1995), for larval lengths of $6.1 \mathrm{~mm}$ or smaller we used $\left(P_{F}, P_{D}\right)=(0.5$ $\left.\mathrm{sec}^{-1}, 1.7 \mathrm{sec}\right)$, whereas for larvae larger than 6.1 $\mathrm{mm}$, we used $\left(P_{F}, P_{D}\right)=\left(0.62 \mathrm{sec}^{-1}, 1.4 \mathrm{sec}\right)$. Finally,

$$
\omega^{2}=1.88(\varepsilon R)^{2 / 3}
$$

is the turbulent velocity (squared), where $\varepsilon$ is the rate of turbulent kinetic energy dissipation which is obtained at every point in space and time throughout the model domain (see Werner et al., 1996).

The number of ith prey category encountered per day is obtained by accumulating over all $i$ th prey encountered $\left(E_{p-t}\right)$ within each $\Delta t$ time step 


$$
N_{c, h}(i)=\sum_{24 \mathrm{~h}} L E_{\mathrm{p}-\mathrm{t}_{c, h}}(i) \Delta t
$$

where $L$ is a day/night binary switch which is unity

Day 20

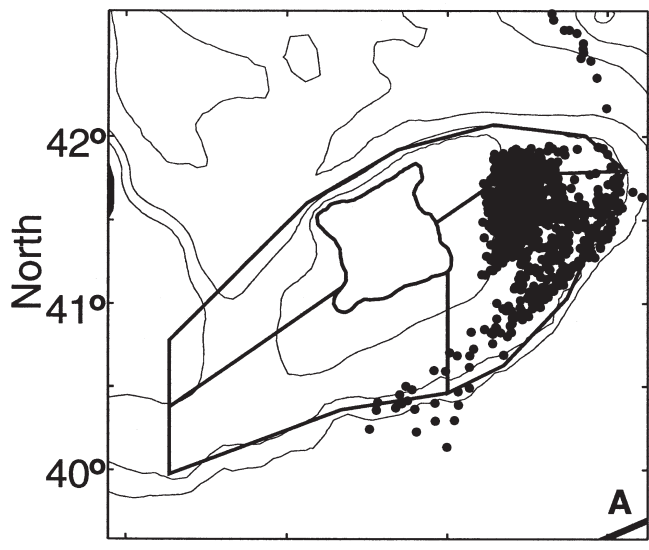

Day 40

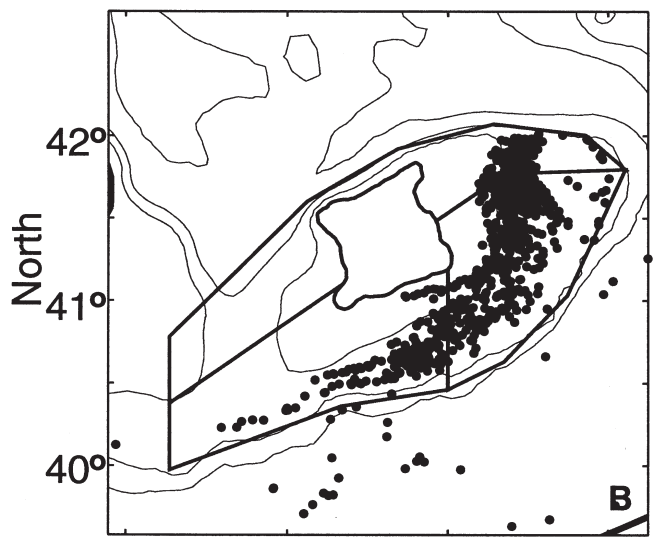

Day 60

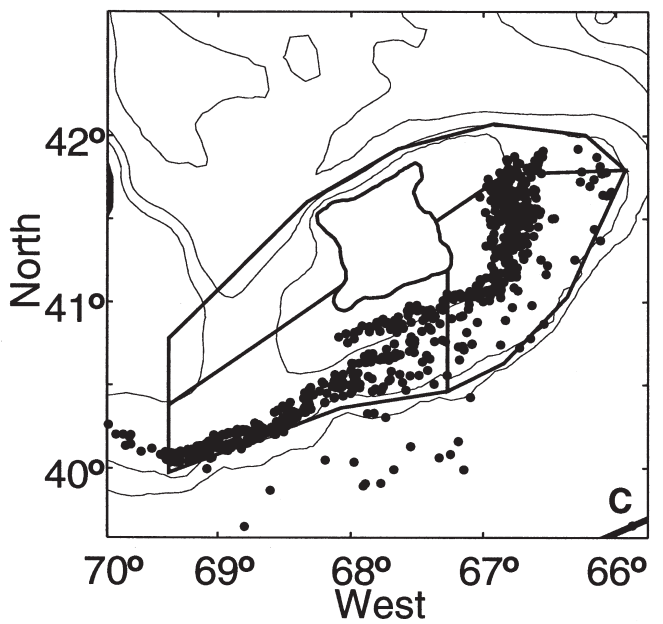

during daylight hours and zero at night, and the $(c, h)$ subscript refers to cod or haddock. The fraction of daylight hours is a function of latitude and day of the year and is computed from Morse (1989).
A

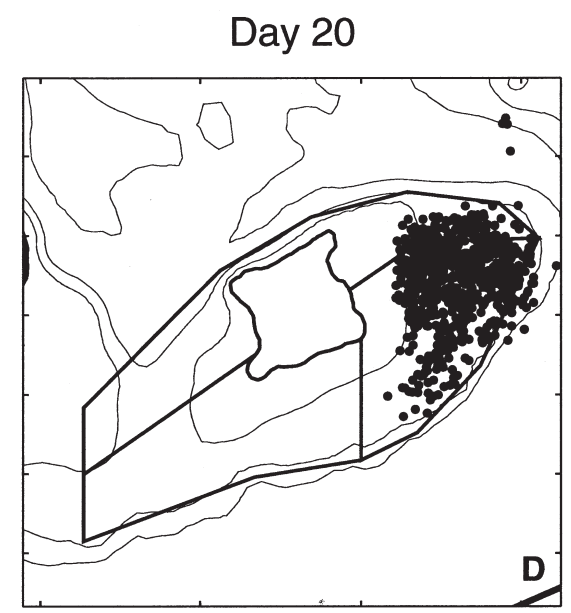

Day 40

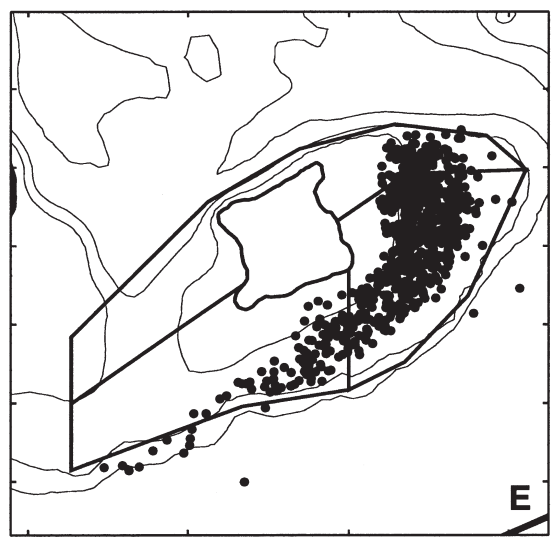

Day 60

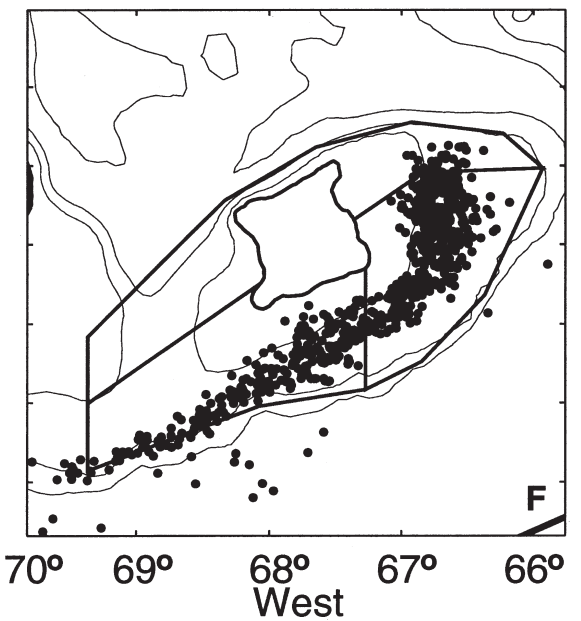

FIG. 4. - Particle locations on George Bank at hatch (day 20 post-spawn), 40 days post-spawn and 60 days post-spawn. The trajectories shown in the three left-most panels (A, B and C) were computed using the time-dependent non-turbulent velocity field. The trajectories shown in the three right-most panels (D, E and F) were computed including the effect of turbulent "kicks" in the vertical (see Section 7). Isobaths and regions as in Fig. 1. 
TABLE 2. - Calculated relationships between total length of cod and haddock larvae, and the minimum and maximum lengths of prey found in their guts. Data source: Fig. 4 of Economou (1991). $\lambda$ denotes prey length $(\mathrm{mm}) ; L$ denotes larval body length $(\mathrm{mm}) ; r$ is the coefficient of determination; and $p$ is the level of significance, where n.s. denotes not-significant.

\begin{tabular}{|c|c|c|c|c|}
\hline $\begin{array}{c}\text { Species } \begin{array}{c}\text { Larva } \\
\text { Range }\end{array}\end{array}$ & $\begin{array}{l}1 \text { Size } \\
(\mathrm{mm})\end{array}$ & Model & $r^{2}$ & $p$ \\
\hline Cod & $6-14$ & $\begin{array}{l}\lambda_{\min }=0.16 \\
\lambda_{\max }=0.106 \mathrm{~L}\end{array}$ & $\begin{array}{l}\text { n.s. } \\
0.56\end{array}$ & $\begin{array}{l}>0.05 \\
<0.0001\end{array}$ \\
\hline Haddock & 4-17 & $\begin{array}{l}\lambda_{\min }=0.12 \\
\lambda_{\max }=0.211 \mathrm{~L}-0.579\end{array}$ & $\begin{array}{l}\text { n.s. } \\
0.94\end{array}$ & $\begin{array}{l}>0.05 \\
>0.05\end{array}$ \\
\hline $\begin{array}{l}\text { Combined } \\
\text { cod and haddock }\end{array}$ & $4-17$ & $\begin{array}{l}\lambda_{\min }=0.00398 \mathrm{~L}+0.09970 \\
\lambda_{\max }=0.193 \mathrm{~L}-0.527\end{array}$ & $\begin{array}{l}\text { n.s. } \\
0.82\end{array}$ & $\begin{array}{l}>0.05 \\
>0.0001\end{array}$ \\
\hline
\end{tabular}

(b) Prey Biomass Ingested. Prey densities were estimated as described in Section 3. However, some sizes of these taxa are not consumed by larval cod and haddock (Kane, 1984; Economou, 1991) because prey whose width is greater than the mouth gape cannot be ingested (e.g., Heath, 1993). In addition, prey behavior may modify the sizes of prey consumed by larval cod and haddock. This sizedependency is apparent from Economou's (1991) observations that the maximal widths of prey found in larval stomachs are much less than the mouth gape, and that maximal lengths and widths of prey consumed increase with both larval length and mouth gape. The observation that prey width is much less than mouth size suggests that when prey exceed a certain size (relative to larval size), prey escape behaviour (possibly as a function of its length) prevents capture (Heath, 1993). Hence when estimating the abundance of prey suitable for consumption by larval fishes it is necessary to exclude certain prey sizes which may be present in the water but which are not consumed.

In previous studies (Werner et al., 1996), we externally imposed a restriction on the availability of particular size classes consumed. This restriction was defined by the proportions of particular size fractions of prey found in larval stomachs (Kane, 1984). However, the size fractions observed by Kane in his gut content analyses may not be constant over time and for all locations on the bank (Lough and Mountain, 1996) because of temporal and spatial variability in prey size distributions (Buckley and Lough, 1987). Hence, prey densities scaled using Kane's gut content size fractions could therefore underestimate the potential prey available for consumption, particularly if larvae feed less selectively when food abundance is low (Munk, 1995).
In the present study, the criterion we chose for limiting the maximal size of prey consumed was derived from the maximum prey-length to larvallength relationships given by Economou (1991; see Fig. 4 therein). These relations (Table 2) were then used to restrict the abundance of potential prey for the different sizes of larval cod and haddock. In a similar fashion we used Economou's (1991) estimates of minimum prey length to derive relationships between larval length and minimum prey length. These relationships enabled us to exclude small prey from abundance estimates as larvae grew.

Rather than specify a single size for each prey category, we assumed the distribution of prey lengths to be Gaussian with means and standard deviations as in Table 1. The lengths of the entire population of a given category were assumed to fall within the mean length $\pm 3 \sigma$. Those prey lengths outside the size range defined by $\lambda_{(c, h) \min }$ and $\lambda_{(c, h) \max }$ (Table 2; Fig. 5) were considered unavailable as prey. Therefore the available prey items $N_{c, h}^{\prime}(i)$ in any given category are some fraction of the total encountered $N_{c, h}(i)$.

In summary, the model prey available to the larvae were based on the maximum and minimum sizes of prey found in larval stomachs. Given this sizebased restriction, we assume that larvae consume all developmental stages of the four copepod taxa Kane (1984) identified as significant components of the larval diet on Georges Bank. In addition, we assume that under low food conditions larvae feed relatively unselectively with respect to prey size or taxa (i.e. larvae ingest prey in amounts proportional to their

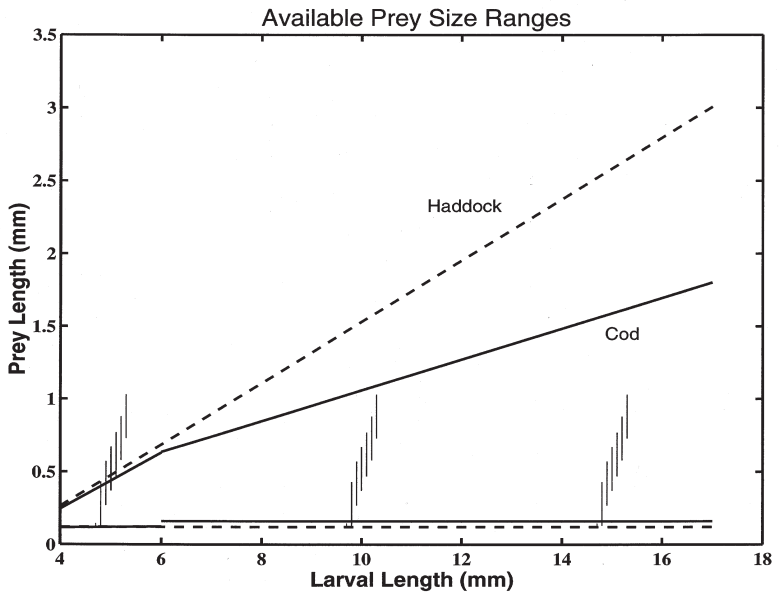

FIG. 5. - Maximal and minimal lengths of prey found in guts of larval haddock and cod larvae as function of larval size. Relationships are calculated from data presented in Economou (1991; Fig. 4 therein). The sloping lines (solid lines correspond to cod larvae, dashed line to cod larvae) correspond to expresions for $\lambda$ in Table 2 ; the prey lengths and $\pm 3 \sigma$ (standard deviations) for the 8 prey (Table 1) are plotted (short vertical lines) three times for ease of reference 
occurrence in the environment). The assumption that larvae feed unselectively when food abundance is low is supported by the observation that cod larvae ingest a much larger size range of prey of the same species when prey abundance is low than when prey abundance is high (Munk, 1995).

The daily prey biomass $P_{c, h}$ ingested by a cod or haddock larva is a function of the number of available prey items encountered $N_{c, h}^{\prime}(i)$

$$
P_{c, h}=\sum_{i=1}^{8}\left[s 1_{c, h} N_{c, h}^{\prime}(i) w_{p}(i)\right]
$$

where $w_{p}(i)$ is the dry weight $(\mu \mathrm{g})$ of the ith prey category (assumed constant within a prey category) and $s 1_{c, h}$ is the swallowing probability of cod and haddock larvae

$$
\begin{aligned}
& s 1_{c}=0.9\left[1-0.667 e^{-0.0040\left(w_{c}-w_{c}^{\text {min }}\right)}\right] \\
& s 1_{c}=0.9\left[1-0.778 e^{-0.0045\left(w_{h}-w_{h}^{m i n}\right)}\right]
\end{aligned}
$$

determined empirically (Laurence, 1985), where $w_{c, h}^{\min }$ is the initial (minimal) observed dry weight at hatch $(\mu \mathrm{g})$ of the cod or haddock larva (taken from Bolz and Lough, 1988).

\section{RESULTS}

In this section we describe the effects of turbulence on encounter rates, capture success and larval dispersion in the model. A brief discussion of the relevant length scales used to estimate the effect of turbulent velocities is provided.
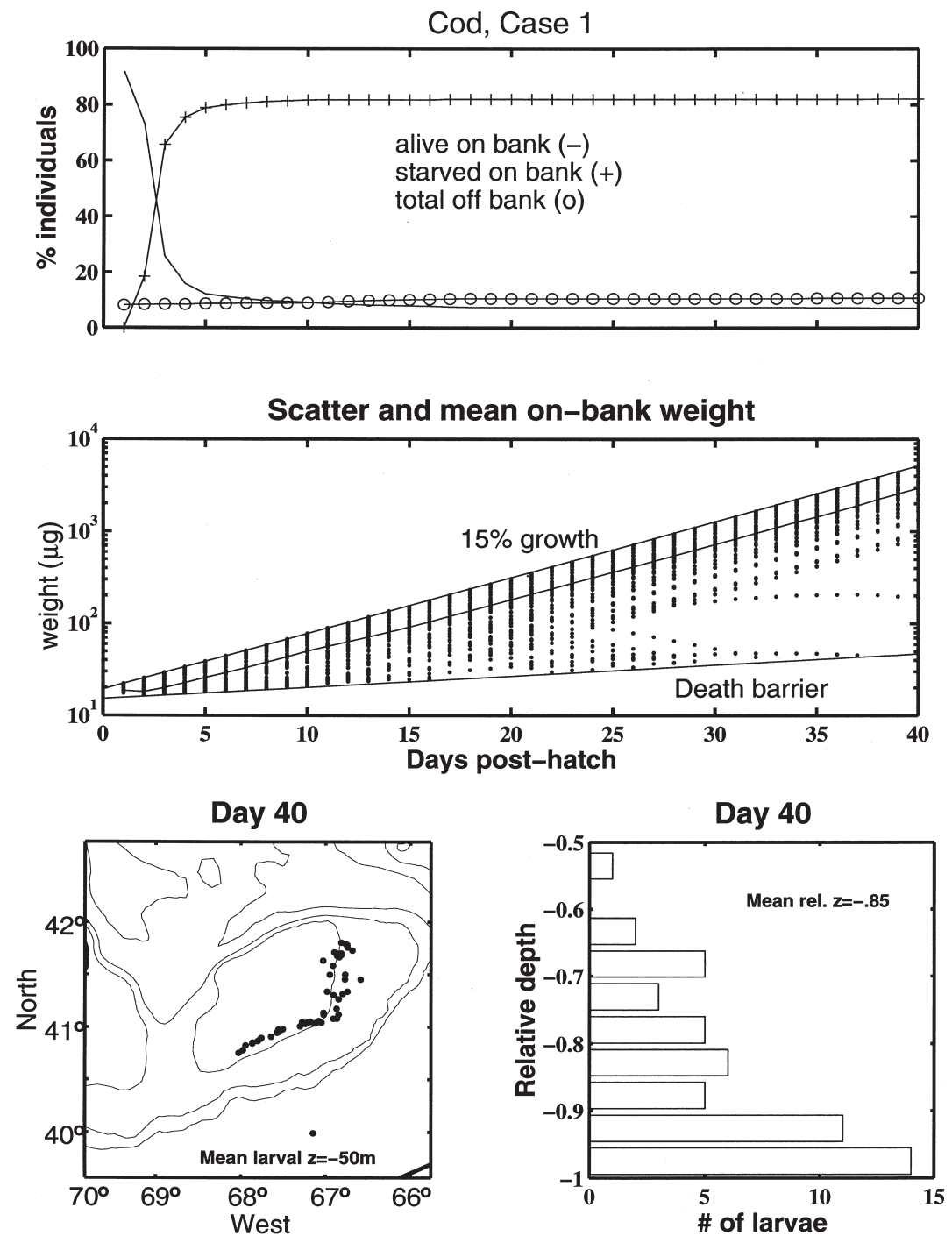

FIG. 6. - Post-hatch time history of cod larvae with $F_{f}=1: 1$ and pause-travel behaviour (Table 3, Case 1). Top panel, the percentage of larvae alive (solid line) starved on-Bank (solid line with crosses) and advected off the Bank (solid line with open circles); second panel, the daily size distribution $(\mu \mathrm{g})$ for the live larvae on the Bank, the $15 \%$ per day growth curve, the death barrier and the mean daily weight of those live lavae still on the Bank. Also shown are the horizontal distribution of the live larvae (bottom left panel) and their vertical distribution relative to the local bottom-depth (bottom right panel). 
TABLE 3. - Summary of percentage of live cod/haddock (c/h) larvae on Georges Bank at day 40, their mean weight ( $\mu$ g) at day 40 , and their mean relative depth $\left(\overline{z_{r}}=\right.$ depth of larvae/local depth; $\bar{z}_{r} \rightarrow 0$ near surface, $\overline{z_{r}} \rightarrow 1$ near bottom) for cases with nomenclature as follows: encounter formulation either pause-travel (P-T), or cruise (C) behaviours; length scale used for estimating turbulent velocity contribution: $R$ for reactive distance (Eq. 2) or $0.55 p^{-1 / 3}$ for mean prey separation distance (where $p$ is prey concentration); $F_{f}=1: 1$ (mean prey concentration as in Table 1 ), or $F_{f}=\mathrm{X}: 1$ (X-fold increase of four smallest prey categories); $\delta$ expected capture success; $M=$ Markov-based turbulent vertical dispersion. Bolz and Lough (1988) measured mean weights of 40-day-old cod larvae of $2466 \mu \mathrm{g}$, and of $4160 \mu \mathrm{g}$ for 40 -day-old haddock.

\begin{tabular}{|c|c|c|c|c|c|c|c|c|c|}
\hline $\begin{array}{l}\text { Case } \\
\#\end{array}$ & $\begin{array}{l}\text { Encounter } \\
\text { Formulation }\end{array}$ & $\begin{array}{l}\text { Turbulent } \\
\text { Velocity }\end{array}$ & $\begin{array}{c}\text { Encounter } \\
\text { Scale }\end{array}$ & $F f$ & $\delta$ & $M$ & $\begin{array}{l}\text { Day } 40 \\
\% \text { alive }\end{array}$ & $\begin{array}{r}\text { Day } 40 \\
\text { Mean } \mu g\end{array}$ & Day $\frac{40}{\bar{z}_{r}}$ \\
\hline 1 & $\mathrm{c} / \mathrm{h}(\mathrm{P}-\mathrm{T})$ & $\omega \neq 0$ & $R$ & $1: 1$ & $=1$ & no & $7 / 0$ & $2948 / 0$ & $0.86 / 0$ \\
\hline 2 & $\mathrm{c} / \mathrm{h}(\mathrm{P}-\mathrm{T})$ & $\omega=0$ & n.a. & $1: 1$ & $=1$ & no & $0 / 0$ & $0 / 0$ & $0 / 0$ \\
\hline 3 & $\mathrm{c} / \mathrm{h}(\mathrm{P}-\mathrm{T})$ & $\omega=0$ & n.a. & $5: 1$ & $=1$ & no & $65 / 0$ & $3524 / 0$ & $0.49 / 0$ \\
\hline 4 & $\mathrm{c} / \mathrm{h}(\mathrm{P}-\mathrm{T})$ & $\omega \neq 0$ & $R$ & $1: 1$ & $<1$ & no & $0 / 0$ & $0 / 0$ & $0 / 0$ \\
\hline 5 & $\mathrm{c} / \mathrm{h}(\mathrm{P}-\mathrm{T})$ & $\omega \neq 0$ & $R$ & $2: 1$ & $<1$ & no & $33 / 0$ & $2507 / 0$ & $0.55 / 0$ \\
\hline 6 & $\mathrm{c} / \mathrm{h}(\mathrm{P}-\mathrm{T})$ & $\omega \neq 0$ & $R$ & $2: 1$ & $<1$ & yes & $50 / 0$ & $1748 / 0$ & $0.50 / 0$ \\
\hline 7 & $\mathrm{c} / \mathrm{h}(\mathrm{C})$ & $\omega \neq 0$ & $0.55 p^{-1 / 3}$ & $1: 1$ & $<1$ & no & $0 / 0$ & $0 / 0$ & $0 / 0$ \\
\hline 8 & $\mathrm{c} / \mathrm{h}(\mathrm{C})$ & $\omega \neq 0$ & $0.55 p^{-1 / 3}$ & $2: 1$ & $<1$ & no & $72 / 0$ & $3648 / 0$ & $0.48 / 0$ \\
\hline
\end{tabular}

\section{Turbulence and encounter rates}

The survival and growth time-history for pausetravel behaviour and $F_{f}=1: 1$ is shown in Figure 6, and summarized in Table 3 (Case 1). The vertical distribution of survivors is skewed to regions where turbulence enhanced-contact rates are greatest, in this case the bottom boundary layer. This general result is as in Werner et al. (1996).

When the effect of turbulence on the number of prey encountered is not included (by setting $\omega=0$ in Eq. 1), no larvae survive (Table 3, Case 2). The time-history of the turbulence-enhanced contact rate for pause-travel larvae that survive the 40-day post hatch simulation is shown in Figure 7 as the ratio of encounters in the presence of turbulence relative to encounters in he absence of turbulence. The enhancement of prey encountered is as much as five-fold for first-feeding larvae and decreases for larger larvae to factors closer to 3 . Note that these larvae spend most of their time within the bottom boundary layer where turbulence levels are greatest (Fig. 3). As expected from Figure 7, if we increase the concentration of the smallest prey items fivefold $\left(F_{f}=5: 1\right)$ in the absence of turbulenceenhanced encounters (Table 3, Case 3), the larvae survive.

No one single formulation has yet parameterised the precise nature of small scale turbulence affecting predator-prey encounters, and different formulations may better represent different limiting cases (Osborn, 1996). The definition of the appropriate length scale to estimate the contribution of turbulence to predator-prey contact rates (e.g. Eq. 2) is still a matter of discussion (Dower et al., 1997). The length scale has been variously defined as the average distance between prey particles (Sundby and
Fossum, 1990; MacKenzie and Leggett, 1991; Sundby, 1995; Werner et al., 1996), the Kolmogorov scale (Muelbert et al., 1994), the eddy separation distance (Davis et al., 1991) and the larval fish reactive distance (e.g. Evans, 1989; MacKenzie et al., 1994; Denman and Gargett, 1995; Kiørboe and MacKenzie, 1995; Visser and MacKenzie, 1998).

We contrasted the pause-travel formulation in which the spatial scale for estimating turbulent velocity is based on larval reactive distance (Case 4, Table 3) to that of a cruise searcher in which the turbulent velocity used to estimate the predator-prey encounter rate is based on the mean prey separation distance (as in Sundby and Fossum, 1990) (Case 7, Table 3). No larvae survive in either case. In both formulations, a doubling of the concentration of the four smallest prey categories results in larval survivorship (see Case 5 and Case 8). However, there is a quantitative difference: survivorship in Case 8 is

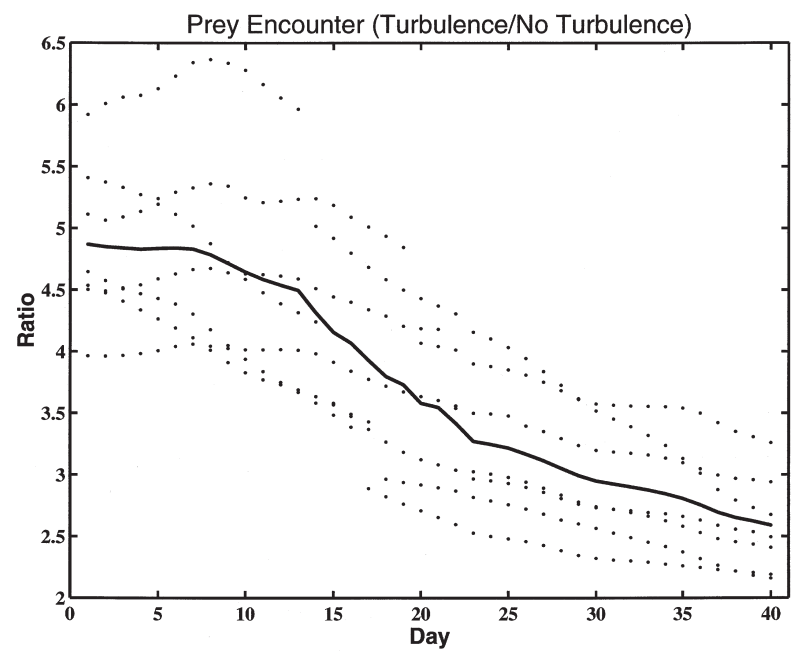

FIG. 7. - Ratio of turbulence enhanced prey encounters (Eq. 1 with $\omega \neq 0$ ) to prey encountered in the absence of turbulence (Eq. 1 with $\omega=0$ ) for seven selected larvae (dots) and the mean value (solid line). 
twice that in Case 5 and growth rates in Case 8 are greater than those observed in the field (Bolz and Lough, 1988) or in Case 5.

\section{Effect of turbulence on capture success}

Models for the influence of small-scale turbulence on larval fish feeding indicate that turbulence can have an overall beneficial or detrimental effect on larval fish ingestion, depending on the magnitude of the turbulence and on larval behavior (Matsushita, 1992; MacKenzie et al., 1994; Jenkinson, 1995; Kiørboe and Saiz, 1995). A dome-shaped relationship is found in which ingestion rates are maximal at intermediate rather than high levels of turbulence; the reduction in pursuit success in highly turbulent environments negates the increase in encounter rate. The relationship can be implemented by scaling the number of prey encountered (Eq. 4) by the expected capture success $\delta$ (see Eq. 27 in Kiørboe and Saiz, 1995). The value of $\delta$ depends on the turbulent velocity $(\omega)$, the larval reaction distance $(R)$, and the reaction time $t_{r}$. Our specification of $\omega$ and $R$ are as described in Section (4a) above; we specify $t_{r}$ as follows.

Pursuit times for cod larvae pursuing prey have been estimated by several authors. Browman (pers. comm. cited in MacKenzie et al., 1994) observed that $4 \mathrm{~mm}$ cod larvae required $1.7 \mathrm{~s}$ to pursue prey whereas $6-7 \mathrm{~mm}$ cod larvae required $1.3 \mathrm{~s}$ to pursue prey in experiments by Munk (1995). MacKenzie and Kiørboe (2000) observed that cod larvae (mean size $10.5 \mathrm{~mm}$ ) required $1-10 \mathrm{~s}$ to pursue prey, and that pursuit time depended on pursuit success and turbulent velocity during the pursuit. No pursuit or feeding behaviour data are available for haddock larvae of any size. To estimate pursuit times for a range of larval haddock and cod sizes, we used Wanzenbock's (1992) data for three species of freshwater larvae attacking live zooplankton prey (Ceriodaphnia reticulata Sars and Eucyclops serrulatus). Mean pursuit time was calculated from each of the three species' size-time relations (see Fig. 1 in Wanzenbock, 1992) at each of the larval sizes used in Wanzenbock's experiments. The overall pursuit time-size relationship we derived from these data is

$$
t_{r}=3.9 L_{c, h}^{-0.60}
$$

where $L_{c, h}$ is the larval cod or haddock length in centimeters, assuming that cod and haddock behave as the freshwater larvae.

This relationship is valid for Wanzenbock's lar-

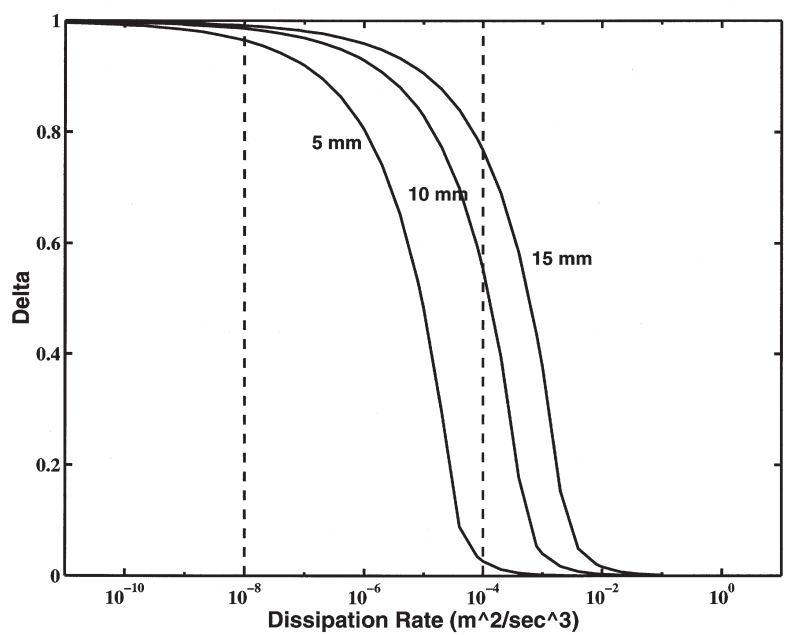

FIG. 8. - Expected capture success $\delta$ as a function of turbulence dissipation rate $\varepsilon$ for three size of larval fish. The vertical dashed lines delimit turbulence levels on George Bank for this study.

vae in the size range $8.5-38.5 \mathrm{~mm}$, and explained $76 \%$ of the variance. We note that if this relationship were extrapolated back to the smaller sizes of cod larvae used in the Browman and Munk experiments, it would yield values nearly identical to those reported by Browman and Munk. This suggests that the pursuit times estimated by this relation may be reasonable approximations of pursuit times for haddock and cod larvae. A plot of $\delta$ as a function of turbulence dissipation rate $\varepsilon$ for three larval sizes is shown in Figure 8. For dissipation ranges found on Georges Bank, values of $\delta$ below 0.5 can be expected for the smallest $(<4-5 \mathrm{~mm})$ larvae, and thus a proportional reduction in number of prey ingested.

The inclusion of $\delta$ in the conditions of Case 1 (Table 3) resulted in no larval survival due to the detrimental effect of turbulence on post-encountercapture success for larvae in these size ranges (Table 3, Case 4).

To partially offset $\delta$ 's detrimental effect, we found that by doubling the concentration of the four smallest prey categories specified in Table 1 (i.e. $F_{f}$ = 2:1; see Fig. 9 and Table 3, Case 5) cod larvae would survive with growth rates comparable to those in Case 1 and comparable to those observed in the field, at least for cod.

\section{Effect of turbulence on larval dispersion}

We have extended our previous studies (Werner et al., 1993, 1996) to consider the effect of random, turbulent "kicks" that modify larval vertical distributions (see also Hannah et al., 1998). We follow the 

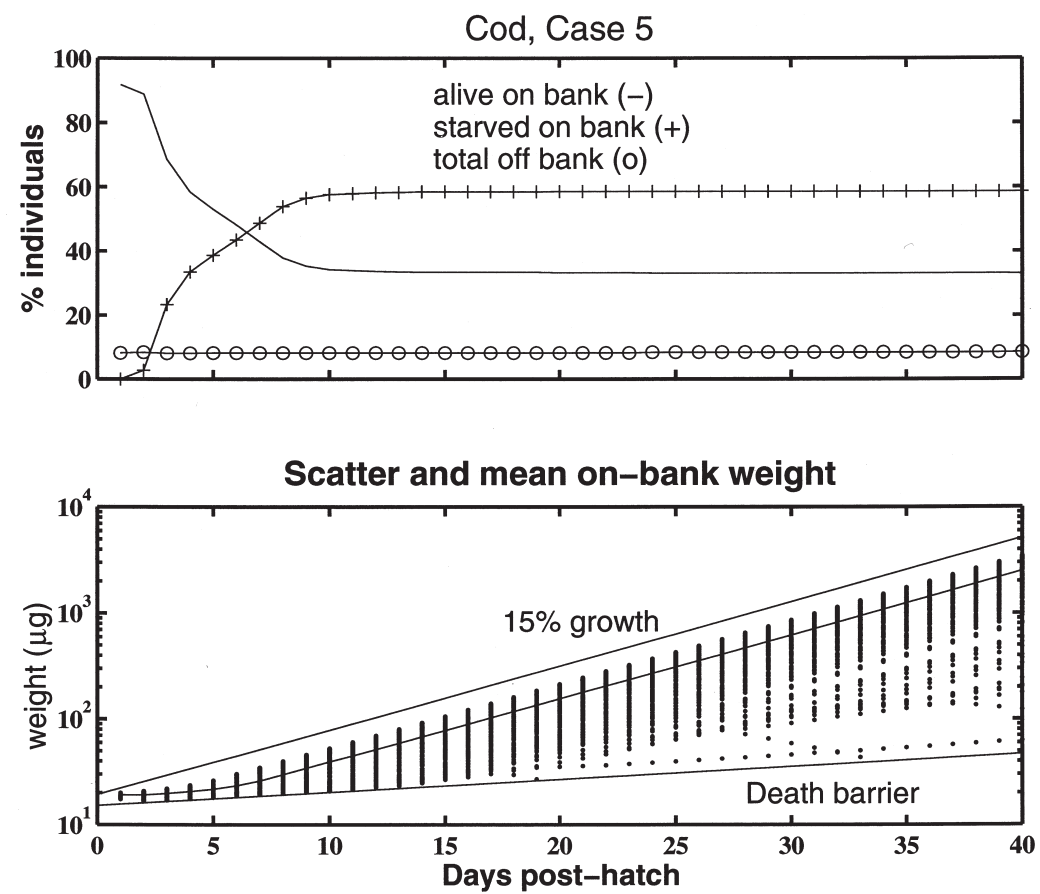

Day 40

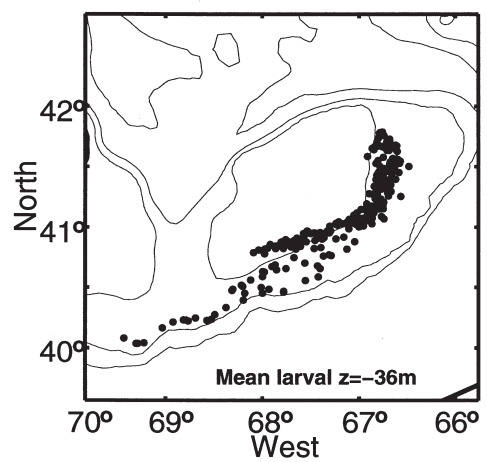

Day 40

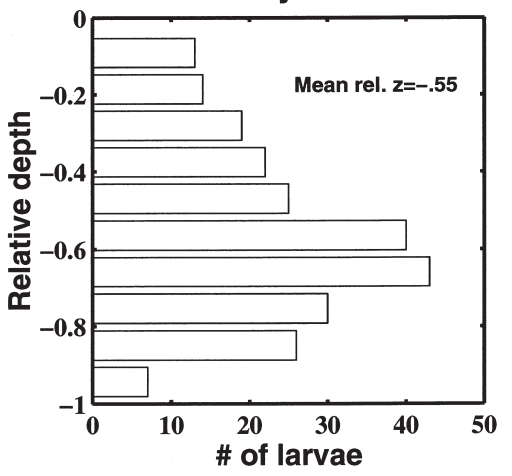

FIG. 9. - As in Figure 6, but $F_{f}=2: 1$ and including $\delta$, the effect of turbulence on the ability of larvae to pursue and capture prey that are encountered (Table 3, Case 6).

approach described by Legg and Raupach (1982) wherein the Langevin equation is used to derive a Markov equation for the vertical velocity of a particle (or larva) in a flow where the turbulence is inhomogeneous. The Langevin equation for the dispersion of particles is

$$
\frac{d w}{d t}=-\alpha w+\lambda \xi(t)+F
$$

where $\alpha=1 / \tau_{l}$ and $\tau_{l}$ is the Lagrangian integral time scale (or auto-correlation time scale) estimated from $N_{q}=\sigma_{w}^{2} \tau_{l}$, where $N_{q}$ is the turbulent exchange coefficient (see Galperin et al., 1988), $\sigma_{w}$ is the Lagrangian velocity variance $\left(\sigma_{w}^{2}=0.3 q^{2} / 2\right) ; \lambda=$ $\sigma_{w}\left(2 / \tau_{l}\right)^{1 / 2} ; \xi(t)$ is Gaussian noise of zero mean and unit variance; and $F=\partial\left(\sigma_{w}^{2}\right) / \partial z$ is a term involving the gradient in the turbulent velocity variance.

The Markov chain for $w_{n+1}$, the turbulent vertical velocity at time step $n+1$, becomes

$$
w_{n+1}=a_{n} w_{n}+b_{n} \sigma_{w n} \xi_{n}+C_{n}
$$

where $a_{n}=\exp \left(-\Delta t / \tau_{l n}\right), b_{n}=\left[1-\exp \left(-2 \Delta t / \tau_{l n}\right)\right]^{1 / 2}$, $C_{n}=(F / \alpha)\left[1-\exp \left(-\Delta t / \tau_{l n}\right)\right]$, and a $\Delta t=1$ minute was used. The computed values of $\tau_{l}$ were of $\mathrm{O}(300) \mathrm{sec}$ (with a standard deviation of $\pm 150 \mathrm{sec}$ ). With turbulent velocity kicks of $\pm 1 \mathrm{~cm} / \mathrm{s}$ (within a standard deviation of zero) turbulent vertical eddy motions of 1.5 to 4 meters are implied.

If the dispersal process is not treated in the above manner, the dispersal of neutrally buoyant particles 
in inhomogeneous turbulent fields can lead to unrealistic aggregations (e.g. Legg and Raupach, 1982; Thomson, 1987; and Holloway, 1994). One of the criteria that must be met is that an initially uniform distribution of particles must remain uniformly distributed over time, i.e. spatial non-uniformities of turbulence intensity cannot "un-mix" an initially well mixed situation. Even in a stratified case, i.e. in the presence of a pycnocline, if there is an initially well mixed distribution of particles, they should remain well mixed over time. Those particles that are initially in the upper (lower) layer will sample mainly the upper (lower) layer, with a finite probability of being "kicked" into the pycnocline. Those particles that are initially in the pycnocline, where turbulence is decreased, will remain in the pycnocline region for longer periods, albeit with a finite probability of being "kicked out" of the pycnocline.
Hence, some particles in stratified cases, initially in the upper (lower) layer, will make it across the pycnocline to the lower (upper) layer. In the end, the net flux of (passive, neutrally buoyant) particles through any depth level should be close to zero, resulting in no net accumulation (or un-mixing) of particles.

In the present set of simulations it is essential to include $F$, the gradient in the turbulent velocity variance. If this term is ignored, particles (larvae) that are released unformily over depth are "kicked out" of the bottom layer (where tidal turbulence is strongest) and are unrealistically accumulated in the surface layers of the water column. A comparison of the trajectories of a particular larva (without turbulent kicks, with turbulent kicks, and with turbulent kicks computed without the term $F$ ) is shown in Figure 10; the mean depth over the 40day larval period was $-38 \mathrm{~m}$ for the non-turbulent
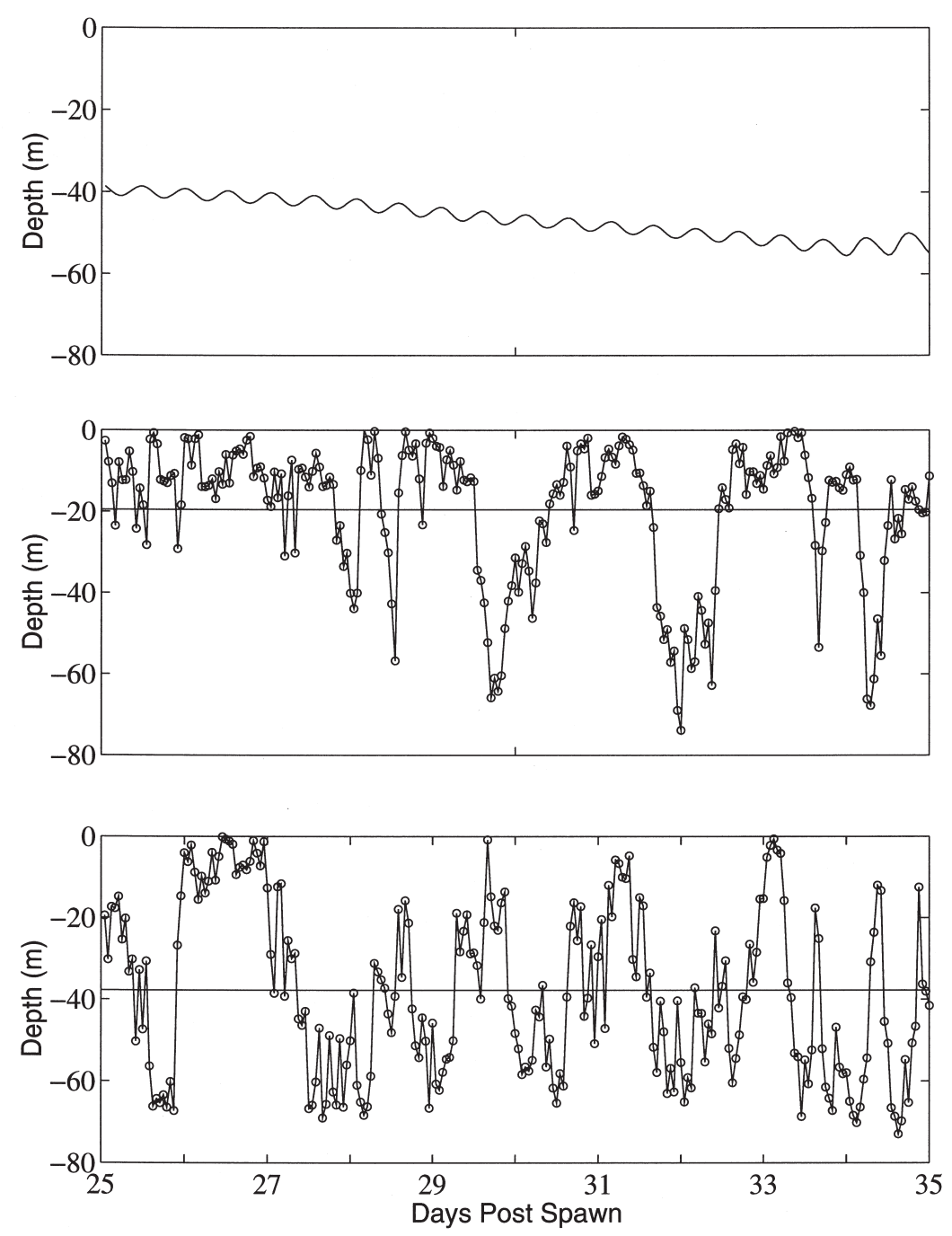

FIG. 10. - Time-history of hourly vertical positions during days 25-35 post-spawn for larva \#350. Top panel: without turbulent "kicks"; middle panel: with the inclusion of vertical "kicks" without the term $F$ in Eq. 12; and bottom panel: with the inclusion of vertical turbulent "kicks" as in Eq. 12. The horizontal lines in the middle and bottom panels indicate the mean depth over the 10-day time period. 
Cod, Case 6
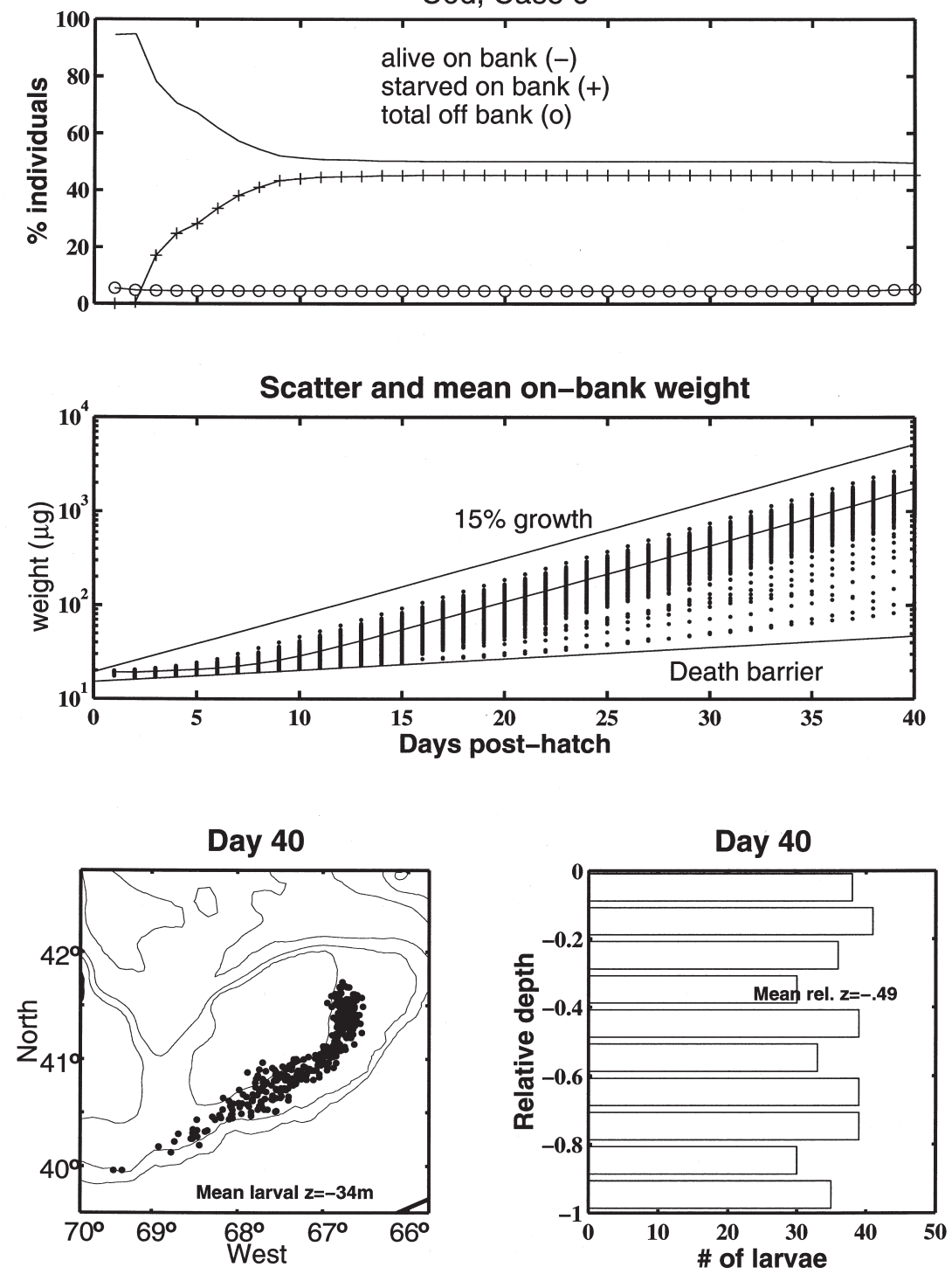

FIG. 11. - As in Figure 9 but with the inclusion of vertical turbulent "kicks" (Table 3, Case 6).

trajectory, $-23 \mathrm{~m}$ for the turbulent trajectory without the gradient in the turbulent velocity variance $(F)$, and $-36 \mathrm{~m}$ for the turbulent trajectory computed using Equation 8.

The survival and growth time-history as in Case 5 and including the effect of turbulent kicks on the computed larval trajectories is shown in Figure 11 and summarised in Table 3, Case 6. This simulation resulted in a population of "average" larvae with reduced variance in size. In the absence of vertical dispersion, the mean length of the larvae at day 40 in Figure 9 is $13.1 \mathrm{~mm}( \pm 1.6 \mathrm{~mm})$, or in terms of dry weight $2507 \mu \mathrm{g}( \pm 901)$. With vertical dispersion (Fig. 11) the mean larval length is $12.1 \mathrm{~mm}( \pm$ $1.10 \mathrm{~mm})$, or $1748 \mu \mathrm{g}( \pm 491)$ in terms of weight. This arises because individual larvae sample the entire water column rather than remaining fixed at particular depths.

\section{SUMMARY AND DISCUSSION}

We examined the effect of turbulence both on predator-prey contact rates (MacKenzie and Kiørboe, 1995) and on the ability of larvae to pursue and capture prey once they are encountered (Kiørboe and Saiz, 1995; MacKenzie and Kiørboe, 2000). These simulations show that larvae would not survive on Georges Bank (Table 3, Case 4) using the food concentrations determined by large-scale plankton samplers as reported by Davis (1984) and Laurence (1985). This result assumes that the larval diet consists of copepod nauplii and copepodites. However, by doubling the concentration of prey in 
the four smallest prey size-classes, and allowing for turbulence-dependent pursuit success, we obtained a larval survivorship for cod and growth rates (Fig. 9; Case 5, Table 3) comparable to those observed in the field (Bolz and Lough, 1988). These increased zooplankton concentrations are well within the range of temporal and spatial variability that has been reported for Georges Bank (e.g. CV $=40$ $121 \%$ for three different sites, Buckley and Lough 1987; see also Davis et al., 1992 and Incze et al., 1996), and also within the range observed inside finescale patches of microzooplankton in turbulent and calm environments (Owen, 1989). It seems likely, therefore, that some larval fish on Georges Bank experience local densities of prey at least twofold higher than the mean concentrations specified in Table 1. If this supposition is true, factors controlling the abundance of prey, and the ability of larvae to locate regions of aggregated prey, should be important to larval survival.

Our finding that modelled cod and haddock larvae cannot survive on Georges Bank (at averaged prey concentrations) is also partly due to the detrimental effects of moderate to high turbulence on larval feeding success. In particular, pursuit success is predicted to decrease from ca. $90 \%$ to $10 \%$ in the dissipation rate range $10^{-7}-10^{-5} \mathrm{~m}^{2} \mathrm{~s}^{-3}$ (Kiørboe and MacKenzie, 1995). These predictions are supported by direct laboratory observations of cod larvae preying on live copepod nauplii and copepodites (MacKenzie and Kiørboe, 2000) which showed that pursuit success declined according to theoretical predictions (MacKenzie et al., 1994; Kiørboe and Saiz, 1995). Notably this range $\left(10^{-7}-10^{-5} \mathrm{~m}^{2} \mathrm{~s}^{-3}\right)$, and higher values, of turbulence are typically found on large areas of Georges Bank (Fig. 3). As a result much of the positive effect of turbulence on encounter rates (Rothschild and Osborn, 1988; Sundby et al., 1994; MacKenzie and Kiørboe, 1995) is offset by negative effects on pursuit ability, and vice versa.

We considered the effect of larval dispersal in the water column due to turbulent motions. Our results (Figs. 10 and 11) suggest that turbulence allows passive (non-swimming, neutrally-buoyant) larvae to sample the entire water column several times over a 40-day period. In other words, larvae that were released in the top (bottom) layers will, through turbulent kicks, be "bumped" to the bottom (top), then back to the top (bottom), etc. The standard deviation of the model turbulent velocities that larvae encounter is of the order of $\pm 1 \mathrm{~cm} / \mathrm{s}$, and hence a larva that is $5-7 \mathrm{~mm}$ in length, if swimming at a body-length per second should be able to sustain its position or even overcome the turbulent "kick". In our case, sampling the entire feeding environment in the vertical results in a reduction in the variance of the larval sizes at the end of 40 days.

Previous studies have described the general twolayer circulation of Georges Bank and found that larvae located in the lower water column and near bottom have an increased probability of remaining on the Bank (e.g. Werner et al., 1993). However, including this turbulent dispersion effect suggests that passive larvae will spend more time in the middle and upper water column where they may be at higher risk of advection off the Bank due to this two-layer circulation and occasional wind or storm events (e.g. Lough et al., 1994). Including the effect of behaviour (e.g. active vertical migration) and the ability to aggregate (e.g. Lough, 1984; Buckley and Lough, 1987; Lough and Potter, 1993; Lough and Mountain, 1996) will be critical to modelling vertical distributions and subsequent horizontal transports observed in the field.

While these results are encouraging, we recognise that the system is much more complex than that portrayed in our study. For example, we have had to extrapolate several biological results obtained with other species and sizes of larvae estimated in calm water experiments to cod and haddock larvae in turbulent water. In addition, we have approximated the distribution of prey both spatially and temporally by specifying only variability at large horizontal scales (i.e. between the four regions on the Bank; Fig. 1), even though variability at smaller scales exists (Davis et al., 1992; see also the model-based study of Lynch et al., 2000). We have also assumed that larvae do not feed until the yolksac has been fully absorbed, although it is evident that cod larvae ingest phytoplankton (Lough and Mountain, 1996), ciliates and other microzooplankton during and after yolksac absorption (Last, 1978; van der Meeren and Næss, 1993; Gallager et al., 1996; Quinlan et al., 1997). By excluding these alternate prey, we have probably disadvantaged our model larvae compared to those in nature. These extrapolations and simplifications were necessary due to a lack of data for cod and haddock, but they enabled us to conduct sensitivity analyses to identify critical inputs worthy of further investigation.

A number of other areas deserve further study but are not part of this model. These include: (i) larval vertical migration; (ii) light-limitations on 
encounter rates in deep water (Huse, 1994; Van Keuren and Gifford, 1996; Fiksen et al., 1998; Grønkjær and Wieland 1997); (iii) effect of turbulence on metabolic rates and growth efficiencies (Saiz and Alcaráz, 1992; Saiz et al., 1992; Dower et al., 1997); (iv) temperature effects on growth (Buckley and Lough, 1987; Leising and Franks, 1999; Buckley et al., 2000); and (v) the inclusion of predators as a possible source of size-selective mortality (e.g. Madin et al., 1996). Our conclusions on feeding and survival must therefore be regarded as preliminary until additional evidence becomes available from field, modelling and laboratory studies of the feeding and growth of larval fishes in environments with different levels of turbulence.

Linking larval fish trophodynamics to dynamic prey fields is a necessary next step in this research. At the same time, the added complexity of more realistic prey distribution will invite advances in approaches to determine behaviour. Externally imposed (and/or passive) behaviours will not make sense in view of the added detail of the feeding environment and will probably be replaced by modelderived behaviours that include components maximising some biological trait, such as reproductive value. Dynamic programming methods and genetic algorithm approaches allow organisms to "find" optimal habitats by balancing risks of predation, growth and advective loss (Giske et al., 1994; Fiksen and Giske, 1995; Fiksen et al., 1998; Huse and Giske, 1998).

Many previous coupled physical-biological models have stressed the importance of vertical position in terms of retention and transport (e.g. see the review by Boehlert and Mundy, 1988). In the present paper, as in Werner et al. (1996), we have seen that larval position in the water column also affects larval feeding success, since turbulence, which enhances encounter rates and affects the probability of capture, is a function of depth. Furthermore, we have noted the sensitivity of growth and survival to larval behavior and to the choice of the turbulent length scale. These results underscore important issues in trophodynamic modelling that will require refinement beyond what we have presented. Our long-term objective is to identify realistic combinations of circulation components and prey-field structures that can reproduce the observed range of growth and survival rates, and to evaluate the relative sensitivity of cod and haddock larvae to aggregated prey distributions and spatially and temporally heterogeneous (turbulent) flow fields. We antici- pate the generation of dynamic prey fields and modification of the larval individual-based-model to include many of the features mentioned in this discussion. Despite the limitations associated with the model, it does provide a framework within which a number of interesting questions can be explored and new data from laboratory and field experiments can be evaluated.

Lastly, the time of year we have considered is late winter/early spring, which is generally weakly stratified. The onset of stratification in late April/early June will result in warmer temperatures which will stimulate growth rates, increased plankton production at both the primary and secondary levels, and suppression of turbulence in the vicinity of the pycnocline where larvae and prey may actively aggregate and form patches due to behaviour or buoyancy effects. These net increases in prey concentration and patchiness (observed by Buckley and Lough, 1987 and Incze et al., 1996) appear to be necessary to achieve field growth rates of cod and (especially) haddock.

\section{ACKNOWLEDGEMENTS}

This research was supported by the joint NSFNOAA U.S. GLOBEC Programme and the Canadian Panel on Energy, Research and Development. This is GLOBEC publication number 134. BRM was supported by a grant from the European Union's Fisheries and Agriculture research programme (AIR2 1994 1226). FEW wishes to thank the organizers and participants of the 1998 Taller y Tertulia de Oceanografía of the Universidad de Las Palmas de Gran Canaria, where some of the ideas presented in this paper were discussed.

\section{REFERENCES}

Alcaraz, M. - 1997. Turbulence and copepods: grazing, behaviour and metabolic rates. In: C. Marrasé, E. Saiz and J.M. Redondo (eds.), Lectures on plankton and turbulence. Sci. Mar., 61: 177-195.

Beyer, J.E. and G.C. Laurence. - 1980. A stochastic model of larval growth. Ecol. Modelling, 8: 109-132.

Beyer, J.E. and G.C. Laurence. - 1981. Aspects of stochasticity in modelling growth and survival of clupeoid fish larvae. Rapp. P.-v. Reun. Cons. int. Explor. Mer, 178: 17-23.

Boehlert, G.W. and B.C. Mundy. - 1988. Roles of behavior and physical factors in larval and juvenile fish recruitment to estuarine nursery areas. American Fisheries Symposium, 3: 51-67.

Bolz, G.R. and R.G. Lough. - 1988. Growth through the first six months of Atlantic cod, Gadus morhua, and haddock, Melanogrammus aeglefinus, based on daily otolith increments. Fish. Bull., U. S., 86: 223-235.

Buckley, L.J. and R.G. Lough. - 1987. Recent growth, biochemical 
composition, and prey field of larval haddock (Melanogrammus aeglefinus) and Atlantic cod (Gadus morhua) on Georges Bank. Can. J. Fish. Aquat. Sci., 44: 14-25.

Buckley, L.J., R.G. Lough, M.A. Peck and F.E. Werner. - 2000. Comment: Larval Atlantic cod and growth models, metabolism, ingestion and temperature effects. Can. J. Fish. Aquat. Sci., in press.

Cushing, D.H. - 1983. Are fish larvae too dilute to affect the density of their food organisms? J. Plankton Res., 6: 591-599.

Davis, C.S. - 1984. Interaction of a copepod population with the mean circulation on Georges Bank. J. Mar. Res., 42: 573-590.

Davis, C.S., G.R. Flierí, P. Wiebe, and P.J.S. Franks. - 1991. Micropatchiness, turbulence and recruitment in plankton. $J$. Mar. Res., 10: 109-151.

Denman, K.L. and A.E. Gargett. - 1995. Biological-physical interactions in the upper ocean: The role of vertical and small scale transport processes. Ann. Rev. Fluid Mech., 27: 225-255.

Dower, J.F., T.J. Miller and W.C. Leggett. - 1997. The role of microscale turbulence in the feeding ecolo of larval fish. Adv. Mar. Biol., 31: 170-220.

Economon, A. N. - 1991. Food and feeding ecology of five gadoid larvae in the northern North Sea. J. Cons. Int. Explor. Mer, 47: 339-351.

Evans, G.T. - 1989. The encounter speed of moving predator and prey. J. Plankton Res., 11: 415-417.

Fiksen, Ø., and J. Giske. - 1995. Vertical distribution and population dynamics of copepods by dynamic optimization. ICES J. mar. Sci., 52: 483-503.

Fiksen, Ø., A.C.W. Utne, D.L. Asknes, K. Eiane, J.V. Helvik and S. Sundby. - 1998. Modelling the influence of light, turbulence and ontogeny on ingestion rates in larval cod and herring. Fish. Oceanogr. 7: 355-363.

Gallager, S.M., L. von Herbing, L. Davis and P. Altalo. - 1996. Yolk-sac cod larvae ingest microzooplankton exclusively from natural plankton assemblages on Georges Bank. EOS, Transactions, American Geophysical Union, 76, Abstract, 0S196.

Galperin, B., L.H. Kantha, S. Hassid, and A. Rosati. - 1988. A quasi-equilibrium turbulent energy model for geophysical flows. J. Atmos. Sci., 45: 55-62.

Giske, J., D.L. Aksnes and Ø. Fiksen. - 1994. Visual predators, environmental variables and zooplankton mortality risk. Vie Milieu, 44: 1-9.

Grønkjær P. and K. Wieland. - 1997. Ontogenetic and environmental effects on vertical distribution of cod larvae in the Bornholm basin, Baltic Sea. Mar. Ecol. Prog. Ser., 154: 91-105.

Hannah, C.G., C.E. Naimie, J.W. Loder and F.E. Werner. - 1998. Upper-Ocean Transport Mechanisms from the Gulf of Maine to Georges Bank, with implications for Calanus Supply. Cont. Shelf Res., 15: 1887-1911.

Heath, M.R. - 1993. The role of escape reactions in determining the size distribution of prey captured by herring larvae: Env. Biol. Fishes, 38: 331-344.

Heath, M.R. and A. Gallego. - 1998. Biophysical modelling of the early life stages of haddock (Melaogrammus aeigeflnus) in the North Sea. Fish. Oceanogr., 7: 110-125.

Hinckley, S., A.J. Hermann and B.A. Megrey. - 1996. Development of a spatially-explicit, individual based model of marine fish early life history. Mar. Ecol. Prog. Ser., 139, 47-68.

Holloway, G. - 1994. Comment: on modeling vertical trajectories of phytoplankton in a mixed layer. Deep-Sea Res., 41: 957-959.

Horne, E.P.W., J.W. Loder and N.S. Oakey. - 1996. Turbulence dissipation rates and nitrate supply in the upper water column on Georges Bank. Deep Sea Res. II Topical Studies in Oceanography, 1683-1712.

Hunter, J.R. - 1972. Swimming and feeding behavior of larval anchovy Engraulis mordax. Fish. Bull., 70: 821-834.

Huse, G. and J. Giske. - 1998. Ecology in Mare Pentium: an individual-based spatio-temporal model for fish with adapted behaviour. Fish. Res., 37: 163-178.

Huse, G. - 1994. Feeding at different illumination levels in larvae of three marine teleost species: cod, Gadus morhna L., plaice, Pleuronectes platessa L., and turbot, Scophthalmus maximus L. Aquacult. Fish. Manage., 25: 687-695.

Incze, L.S., P. Aas and T. Amaire. - 1996. Distribution of copepod nauplii and turbulence on the southern flank fo Georges Bank: implications for feeding by larval cod. Deep Sea Res. II Topical Studies in Oceanography, 1855-1874.

Jenkins, G.P. - 1989. Micro- and fine-scale distribution of microplankton in the feeding environment of larval flounder.
Mar. Ecol. Prog. Ser., 43: 233-244.

Kane, J. - 1984. The feeding habits of co-occurring cod and haddock larvae. Mar. Ecol. Prog. Ser., 16: 9-20.

Kiørboe, T. and B.R. MacKenzie. - 1995. Turbulence-enhanced prey encounter rates in larval fish: effects of spatial scale, larval behaviour and size. J. Plankton Res., 17: 2319-2331.

Kiørboe, T. and E. Saiz. - 1995. Planktivorous feeding in cal and turbulent environments, with emphasis on copepods. Mar. Ecol. Prog. Ser., 122: 135-145.

Last, J.M. - 1978. The food of three species of gadoid larvae in the Eastern English Channel and Southern North Sea. Mar. Biol. 48: 377-386.

Laurence, G.C. - 1978. Comparative growth, respiration and delayed feeding abilities of larval cod (Gadus morhua) and haddock (Melanogrammus aegleflnus) as influenced by temperature during laboratory studies. Mar. Biol., 50: 1-7.

Laurence, G.C. - 1985. A report on the development of stochastic models of food limited growth and survival of cod and haddock larvae on Georges Bank. In: G.C. Laurence and R.G. Lough (eds), Growth and survival of larval fishes in relation to the trophodynamics of Georges Bank cod and haddock, pp. 83-150. NOAA Tech. Mem., NMFS-F/NEC-36, 83-150.

Legg, B.J. and M.R. Raupach. - 1982. Markov chain simulation of particle dispersion in inhomogeneous flows: The mean drift velocity induced by a gradient in Eulerian velocity variance. Boundary-Layer Meteorol., 24: 3-13.

Leising, A.W. and P.J.S. Franks. - 1999. Larval Atlantic cod (Gadus morhua) and haddock (Melanogrammus aelgeflnus) growth on Georges Bank: a model with temperature, prey size and turbulence. Can. J. Fish. Aquat. Sci., 56: 25-36.

Loder, J.W., K.F. Drinkwater, N.S. Oakey and E.P.W. Horne. 1993. Circulation, hydrographic structure and mixing at tidal fronts: the view from Georges Bank. Phil. Trans. R. Soc. Lond. A, 343: 447-460.

Lough, R.G. - 1984. Larval fish trophodynamic studies on Georges Bank: sampling strategy and initia results. In: The propagation of cod Gadus morhua L., E. Dahl, D.S. Danielssen, E. Moksness and P. Solemdal, eds. Flodevigen rapportser, 1: 395-434.

Lough, R.G. and D.G. Mountain. - 1996. Effect of small-scale turbulence on feeding larval cod and haddocl in stratified water on Georges Bank. Deep Sea Res. II Topical Studies in Oceanography, 1745-1772

Lough, R.G. and D.C. Potter. - 1993. Vertical distribution patterns and diel migrations of larval and juvenile haddock Melanogrammus aegleflnus and Atlantic cod Gadus morhua on Georges Bank. Fish Buil U.S., 91: 281-303.

Lough, R.G., W.G. Smith, F.E. Werner, J.W. Loder, F.E. Page, C.G. Hannah, C.E. Naimie, R.I. Perry M. Sinclair and D.R. Lynch. - 1994. Influence of wind-driven advection on interannual variability in cod egg and larval distributions on Georges Bank: 1982 vs 1985. ICES mar. Sci. Symp., 198: 356-378.

Lynch, D.R., J.T.C. Ip, C.E. Naimie and F.E. Werner. - 1996. Comprehensive coastal circulation mode with application to the Gulf of Maine. Cont. Shelf Res., 16: 875-906.

Lynch, D.R., C.V.W. Lewis and F.E. Werner. - 2000. Can Georges Bank Larval Cod Survive on a Calanoid Diet? Deep Sea Res. II, in press.

MacKenzie, B.R. and T. Kiørboe. - 1995. Encounter rates and swimming behavior of pause-travel and cruise larval fish predators in calm and turbulent environments. Limnol. Oceanogr., 40: $1278-1289$.

MacKenzie, B.R. and T. Kiørboe. - 2000. Larval fish feeding and turbulence: a case for the downside. Limnol. Oceanogr., 45: 1-10.

MacKenzie, B.R. and W.C. Leggett. - 1991. Quantifying the contribution of small-scale turbulence to the encounter rates between larval fish and their zooplankton prey: effects of wind and tide. Mar. Ecol. Prog. Ser., 73: 149-160.

MacKenzie, B.R., T.J. Miller, S. Cyr and W.C. Leggett. - 1994 Evidence for a dome-shaped relationship between turbulence and larval fish ingestion rates. Limnol. Oceanogr., 39: 17901799.

Madin, L.P., S.M. Bollens, E. Horgan, M. Butler, J. Runge, B.K. Sullivan, G. Klein-Macphee, E. Durbin D. Van Keuren, S. Plourde, A. Bucklin and M.E. Clarke. - 1996. Voracious planktonic hydroids: un expected predatory impact on a coastal marine ecosystem. Deep Sea Res. II Topical Studies in Oceanography, 1823-1829.

Marrasé, C., E. Saiz and J.M. Redondo (eds.). - 1997. Lectures on 
plankton and turbulence, Sci. Mar., 61(Supl. 1): 1-238.

Mellor, G.L., and T. Yamada. - 1982. Development of a turbulence closure model for geophysical fluid problems. Rev. of Geophys. Space Phys., 20: 851-875.

Muelbert, J.H., M.R. Lewis and D.E. Kelley. - 1994. The importance of small-scale turbulence in the feeding of herring larvae. J. Plankton Res., 16: 927-944.

Munk, P. - 1995. Foraging behaviour of larval cod (Gadus morhua) influenced by prey density and hunger Mar. Biol., 122: 205-212.

Munk, P. and T. Kiørboe. - 1985. Feeding behaviour and swimming activity of larval herring (Clupea harengus) in relation to density of copepod nauplii. Mar. Ecol. Prog. Ser., 24: 15-21.

Naimie, C.E. - 1995. On the Modelling of the Seasonal Variation of the Three-Dimensional Circulation Near Georges Bank, PhD Dissertation, Dartmouth College, Hanover, New Hampshire, 266 pp.

Naimie, C.E. - 1996. Georges Bank residual circulation during weak and strong stratification periods prognostic numerical model results. J. Geophys. Res., 101: 6469-6486.

Osborn, T. - 1996. The role of turbulent diffusion for copepods with feeding currents. J. Plankton Res. 18: 185-195.

Owen, R.W. - 1989. Microscale and finescale variations of small plankton in coastal and pelagic environ ments. J. Mar. Res., 47: 197-240.

Page, F.H., and K.T. Frank. - 1989. Spawning time and egg-stage duration in Northwest Atlantic haddocl (Melanogrammus aegleflnus) stocks with emphasis on Georges and Browns Bank. Can. J. Fish. Aquat. Sci., 46 (Suppl. 1): 68-81.

Quinlan, J.A., F.E. Werner, S. Gallager, R.G. Lough and L.J. Buckley. -1997 . Modeling the role of microzooplankton grazing in the feeding environment of yolk-sac cod larvae. ICES Annual Science Conference, 25-30 September 1997, Baltimore, MD, USA. ICES C.M. 1997/T: 15.

Rothschild, B.J. - 1992. Application of stochastic geometry to problems in plankton ecology. Phil Trans. R. Soc. Lond., B336: 225-237.

Rothschild, B.J. and T.R. Osborn. - 1988. Small-scale turbulence and plankton contact rates. J. Plankton Res., 10: 465-474.

Sundby, S. and P. Fossum. - 1990. Feeding conditions of ArctonNorwegian cod larvae compared with the Rothschild and Osborn theory on small-scale turbulence and plankton contact rates. J. Plankton Res., 12: 1153-1162.

Sundby, S. - 1995. Wind climate and foraging of larval and juvenile arcto-norwegian cod (Gadus morhua). In: R.J. Beamish (ed.), Climate change and northern fish populations, Can. Spec. Publ. Fish. Aquat. Sci., 121: 405-415.

Thomson, D.J. - 1987. Criteria for the selection of stochastic models of particle trajectories in turbulent flows. J. Fluid Mech., 180: 529-556.

Van Keuren, J.R. and D.J. Gifford. - 1996. Optical/biological interactions on Georges Bank between January and July 1995. EOS, Transactions, American Geophysical Union, 76, Abstract, 0S197.

van der Meeren, T. and T. Næss. - 1993. How does cod (Gadus morhua) cope with variability in feeding conditions during early larval stages? Mar. Biol., 116: 637-647.

Visser A.W. and B.R. MacKenzie. - 1998. Turbulence-induced contact rates of plankton: the question of scale. Mar. Ecol. Prog. Ser., 166: 307-310.

Wanzenbock, J. - 1992. Ontogeney of prey attack behaviour in larvae and juveniles of three European cyprinids. Env. Biol. Fishes, 33: 23-32.

Werner, F.E., F.H. Page, D.R. Lynch, J.W. Loder, R.G. Lough, R.I. Perry, D.A. Greenberg and M.M. Sinclair. - 1993. Influences of mean advection and simple behavior on the distribution of cod and haddock early life stages on Georges Bank. Fish. Oceanogr., 2: 43-64.

Werner, F.E., R.I. Perry, R.G. Lough and C.E. Naimie. - 1996. 
